\section{Fission wastes under glass}

from a Correspondent

Down among the vineyards freshly laden with grapes, and the arid scrublands of Provençal France, environmental pollution is entering a new phase of test and contestation. The Phénix fast-breeder reactor, which went critical in late summer 1973 and fully operational last year, has now produced a full year's electrical supply of its net annual output of 233 megawatts (a trifle under one-hundredth the current yield of the entire French national power grid). Situated on the Rhone River at Marcoule in an atomic energy installation inaugurated in 1953, Phénix once again reminds both the public and specialists of nuclear energy's number-one nag: what happens to the radioactive wastes?

To help answer the question, and capitalising on a Canadian idea, Phénix's technical managers - the Commissariat à l'Energie Atomique and Electricité de France-have spent the past six years exploiting their PIVER process of vitrification. The idea is to treat and then store in a minimal volume, irradiated fuel residues in a stable and inert form. PIVER is a chemical incorporation, rather than merely a physical packaging, involving the fusion of waste materials with glass containing aluminium compounds, after the elimination of nitrogen oxides and various volatile products of fission.

The waste-glass amalgam is cast into blocks of $100 \mathrm{~kg}$ each, poured from Inconel stainless steel pots $25 \mathrm{~cm}$ in diameter and $2.50 \mathrm{~m}$ tall. The blocks are then stored on the spot in concretesheathed, vertical tubes $10 \mathrm{~m}$ deep. The process is said to make the waste material as insoluble as is chemically and physically possible, confine the radiation trapped inside (a batch of 12 vitrified tons confines 4 million curies), and provide good thermal stability during the early cooling and first 10-15 years of storage. PIVER regularly handles 14 tonnes of irradiated waste, in two semi-weekly operations. The vitrified blocks are eventually removed from their storage shafts to a halfburied, more isolated site.

But is this enough? Even the Commissariat's Yves Sousselier, a chemist, asks, "Will there always be radioactive wastes?" Recently, a group of forty professors from the Collège de France circulated a petition to the Parisian government calling for a halt to all nuclear energy activity. But the government is proceeding with plans to start work later this year on Super-Phénix, a 1,200 megawatt breeder reactor to be built further upstream along the Rhône at Creys-Malville.

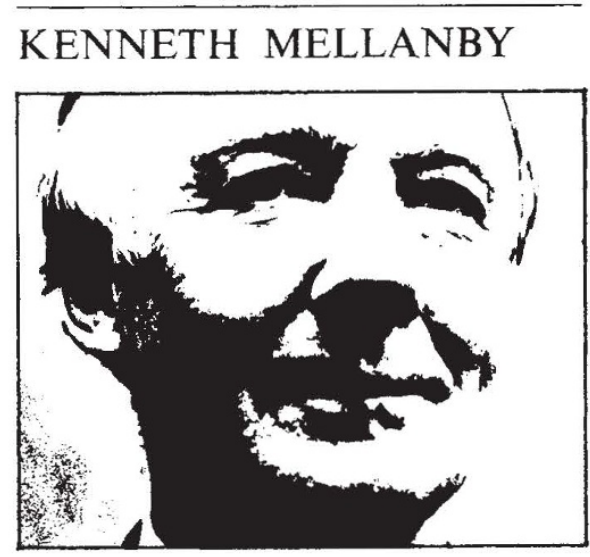

\section{Treble recorder}

ChILDREN in Britain and other western countries are larger and heavier than were individuals of the same age a hundred, fifty, or even only thirty-five years ago. This is usually considered to be a sign of better nutrition, though reports of obesity-perhaps our commonest form of malnutrition--are disturbingly common. But even without the disadvantage of fatness, is the present type of feeding doing good or harm? We know that rats which have an apparently suboptimal diet when young live longer than their littermates given a more liberal diet. It will be interesting to find whether the total life span of the present generation of children is longer or shorter than that of those who, for instance, were reared during the slump in the nineteen thirties, or who had the advantage of war-time rations.

It is generally believed that as well as growing faster, children become sexually mature earlier than they did in previous times. There are many publications which are believed to prove this point. All are based on observations on girls, and describe the age of the menarche in different communities. It is said that this was quite young (eleven or twelve) in the Middle Ages, that it rose to sixteen or more years, at least in Scandinavia, in the nineteenth century, and that it has since fallen steadily to a figure similar to that found three or four hundred years ago.

These results obtained from girls, are not universally accepted, for some of the records of the phenomenon on which they are based, derived largely from orphanage records, are somewhat suspect. Also I have heard the topic discussed by a group of women scientists who are now in their nineties; they considered that they and their school friends, towards the end of the last century, were as precocious as the present generation. However, it was pointed out that they came from comfortable middle class homes, and that things might have been different among the ill-fed poor.

It always seems to me strange that there have been hardly any studies on boys, for here the onset of puberty could be so much more easily studied without the need for the sort of information which must have been hard to obtain among prudish Victorians. Some years ago I was involved in a pilot study of this subject, and I obtained the cooperation of Walter James, then editor of the Times Educational Supplement. I wished to find out whether there had been any change in the age at which boy's voices were observed to break. I thought it likely that we could find accurate records for this in the many choir schools attached to cathedrals and colleges in England.

The results of our study were, perhaps, surprising. We found that in the six schools investigated, there had been no significant change between the eighteen nineties and 1960. During the whole period boy's voices had broken, on an average, at a month or two after their thirteenth birthdays. Our preliminary figure suggested that there might have been a fall in this age by a few months in the seventy or so years covered by the investigation, but this was found to be a reflection of changes in the school system and not of the boy's physiology. At one time most choirboys remained at a choir school until the end of the session in which they ceased to sing treble; they now tend to be whisked off to a different school as soon as their voice breaks.

Our findings were briefly noted in Walter James' newspaper, and have received no notice from those concerned with this problem of allegedly earlier maturity. I think that the problem does warrant a much more exhaustive study. Discussion with school masters, particularly choir masters, suggests that there has indeed been little fall in the age of puberty of boys of all classes. This clearly has many sociological implications. But it does also mean that the female figures should be re-scrutinised. Both boys and girls have increased in height and weight in a parallel manner; it is strange that girls, apparently, should differ so much from boys in the change in the age of puberty.

- When I last referred to research contracts (May 1) I complained that they were often small and complicated to operate. In the majority of cases this is only too true. Unfortunately I gave the impression that the worst offenders might be found in the Department of Agriculture, Fisheries and Food. I am glad to be able to report that this is not so. Dr H. C. Pereira, the Chief Scientist, has been able to issue many sensible and simple contracts usually for very large sums. 